\title{
Organisational Culture and Occupational Health a Possible Relationship?
}

\author{
Mari-Lize Nel \\ N Martins \\ Department of Industrial and Organisational Psychology \\ martin@unisa.ac.za
}

\section{Doi:10.5901/mjss.2014.v5n20p2238}

\section{Abstract}

The aim of the study was to test the theoretically developed model and, secondly, to determine whether there is a relationship between organisational culture and occupational health (somatic symptoms, anxiety and insomnia). A quantitative methodology was adopted by means of a survey, which targeted a population of 462 staff members in an Information and Communications Technology (ICT) organisation. The General Health Questionnaire and the South African Culture Instrument were used for this purpose. Structural equation modelling (SEM) was used to determine possible relationships between the constructs, and regression analysis was conducted to determine the predictability of dimensions. The indices indicated that the developed model could be accepted, and this confirmed that health can have an impact on organisational culture or vice versa. The multiple regression analysis results showed that organisational strategy and task systems, as dimensions of organisational culture, predict occupational health most accurately.

Keywords: Organisational culture, occupational health, health symptoms, structural equation modelling (SEM), regression analysis, correlation analysis, fit indexes

\section{Introduction}

Organisational health matters impact businesses in areas such as productivity and profitability. Although much research has been conducted in the domain of organisational culture, the relationship between occupational health and organisational culture (or the impact of one on the other) has not, to the knowledge of the researchers, been researched to date. In order to understand the relationship between occupational health and organisational culture, a systematic methodological approach such as structural equation modelling (SEM) is suggested.

The World Health Organization (Leka, Griffiths \& Cox, 2003) explains that organisational culture is concerned with how problems are recognised and solved. The organisational culture can affect what is experienced as stressful, how the experience translates into health difficulties, how both health and stress are reported and how the organisation responds to such reports. Various organisations recognise the powerful and positive value of psychological insights and knowledge to create healthier work environments. A work-life organisational culture, for example, addresses the managerial dimension of organisational health and is also applicable to a wide range of issues such as work-life balance, burn-out, depression and employee assistance programmes (Quick, Macik-Frey \& Cooper, 2007). Influences, internal or external, can force organisations to adapt or change their current status. According to Kinnear \& Roodt (1998), external forces stimulate change more than internal forces do. It is therefore essential for organisations to identify organisational culture issues in order to promote competitiveness.

\section{Organisational Culture}

A literature review of studies on culture has identified the two major disciplinary foundations of organisational culture, namely the sociological foundation (organisations have cultures) and the anthropological foundation(organisations are cultures). Researchers agree that the concept of cultures refers to the values, underlying assumptions, expectations and definitions that characterise organisations and staff (Cameron \& Quinn, 2011).

Most researchers maintain that organisational culture is an important social characteristic that influences organisational, group and individual behaviour (Hartnell, Ou \& Kinicki, 2011). The dominance and coherence of culture has been proven to be an essential quality of excellent companies, according to Peters and Waterman (Shaw, 1997). Moreover, the stronger the culture and the more it is marketplace directed, the less need there is for policy manuals, 
organisation charts or detailed procedures and rules. In these effective companies, people at all levels know what they are supposed to do in most situations because the handful of guiding values is crystal clear.

The following definition will be used for the purpose of the study: "Organisational culture is an integrated pattern of behaviour, which is unique to a particular organisation and which originated as a result of the survival process and interaction with its environment. Culture directs the organisation to goal attainment. Newly appointed employees must be taught what the correct way of behaving is" (Martins \& Coetzee 2007, p. 21). A number of dimensions and models have been proposed to describe organisational culture because it is extremely broad and extensive scope. No framework is comprehensive, and no framework can be said to be right and others wrong. Instead, the most appropriate framework should be used on the basis of empirical evidence (Cameron \& Quinn, 2011).

After reviewing a number of organisational culture models, the researchers decided to use Martins' model. The model was developed in the South African context and can be used in any organisation (Martins \& Von der Ohe, 2003). The model is based on the interaction between the organisational sub-systems (goals and values, and structural managerial, technological and psychological sub-systems) and the two survival functions, namely the external environment (social, industrial and corporate culture) and the internal systems (artefacts, values and basic assumptions). Martins' model aims to explain complex interaction, which takes place at different levels between individuals and groups and also with other organisations and the external environment, which can be regarded as the primary determinants of behaviour in the workplace (Martins \& Martins, 2002). See Figure 1.

Figure1: Martins' Organisational Culture Model

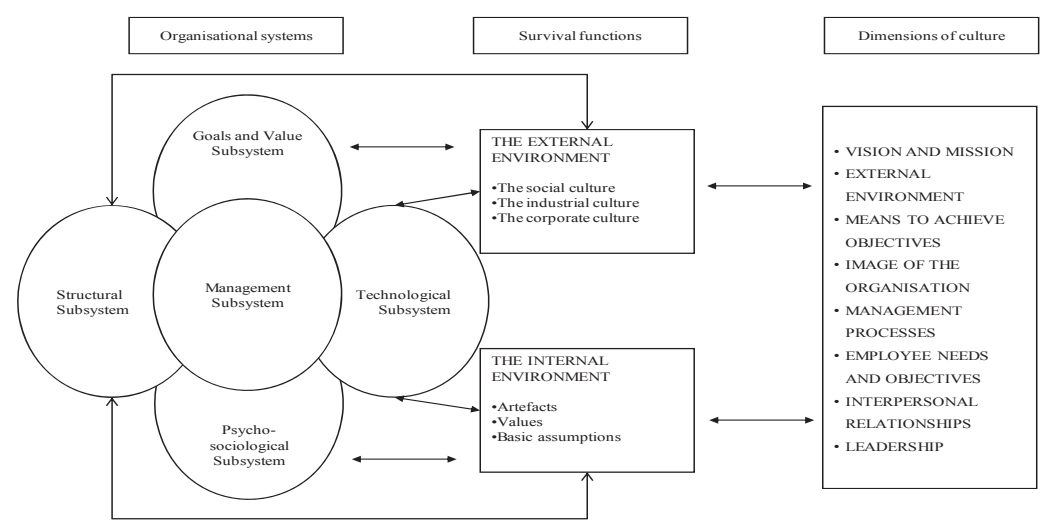

Source: Martins and Von der Ohe (2003, p. 134).

\section{Occupational Health}

Work and health psychology could be described as a sub-discipline of psychology, concerned with the promotion of health and the ability of people to function effectively in working organisations (Winnubst \& Diekstra, 1998). Mathis and Jackson (1982, p. 385) define health as "a general state of physical, mental and emotional well-being". Barling and Griffiths (2003) explain that occupational psychology is not a recent phenomenon. "Indeed, for much of the twentieth century the way in which workplace practices and policies, supervision, and leadership affect employees' physical and psychological well-being has attracted a considerable amount of interest." Recognition of the importance of the more intangible aspects of work and their effects on individual health, both psychological and physical, began to emerge in the nineteenth century, particularly after the Industrial Revolution.

Matters of occupational health, such as stress in the workplace, are not only a major problem for the individual but also for organisations and society. Stress can have adverse effects, primarily on physical and mental health. "Stress is a complex dynamic process in which stressors, enduring health outcomes and modifying variables are all interrelated. Whether a stressor produces an enduring health outcome or not depends on the extent to which the person perceives the condition as stressful and responds to it. His or her perception and response are affected by a number of modifying 
variables, but mainly by his or her personal and social resources" (Oginska-Bulik, 2005, p. 234). Furthermore, according to Cummings and Worley (2005), stress refers to the reactions of people to their environment. It involves both physiological and psychological responses to environmental conditions, causing people to change or adjust their behaviour.

The changing nature of work - due to such factors such as globalisation and increases in international competition - leads to increased levels of stress for companies and individuals alike. These factors highlight the importance of safe and healthy environments to ensure optimal functioning. The purpose of occupational health psychology is to develop, maintain, and promote the health of employees directly, as well as the health of their families (Quick \& Tetrick, 2003). III health occurs when environmental demands or constraints are perceived by a person to exceed his or her capabilities or resources (Jackson, Rothmann \& Van de Vijver, 2006).

\section{Occupational Health and Organisational Culture}

Organisational culture can affect both organisational outcomes such as absenteeism, safety and quality and individual outcomes such as aggression and health (Keyton, 2011). Factors such as values, interest and power on the other hand can influence organisational culture either positively or negatively and can also be a source of occupational health (Prilleltensky \& Prilleltensky, 2006). Based on the literature study in the areas of organisational culture and occupational health, a theoretical model was developed. As illustrated in Figure 2, the aim of the theoretical model was to conceptualise the relationship between organisational culture and occupational health.

As indicated, organisational culture is made up of various elements including change management, interpersonal relations, management processes, organisational strategy, task systems and the technical environment." The definition of health arrived at by Mathis and Jackson (1982, p. 385) states that health is "a general state of physical, mental and emotional well-being". This paper focuses on anxiety and insomnia, social dysfunction and somatic symptoms to indicate the health status of the individuals who participated in the study and the relationship with organisational culture, by means of SEM.

Figure 2: The Relationship between Occupational Health and Organisational Culture

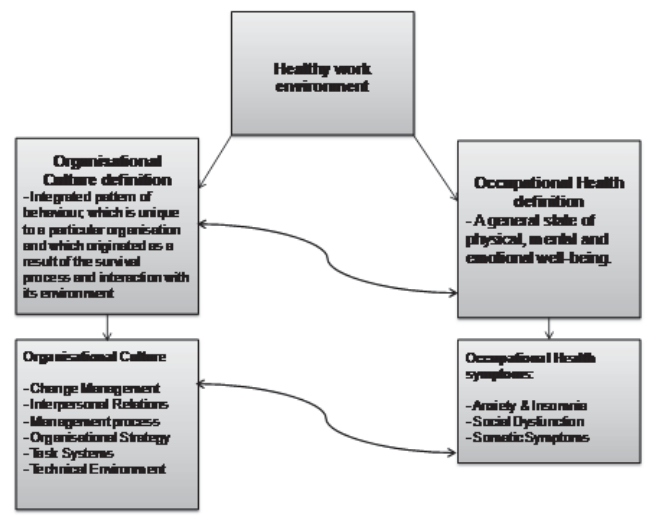

According to Grawitch, Ledford, Ballard and Barber (2009), a healthy workplace is not simply one in which employees eat healthy food, exercise and reduce their physically unhealthy behaviours. Instead, the organisation needs to adopt a comprehensive approach to optimising both employee and organisational outcomes. To create a healthy workplace, employees must be actively involved in shaping organisational practices. Effective employee involvement will increase employee ownership of new programmes and policies and this, in turn, will allow the practices to become more easily integrated into the organisational culture.

\section{Method}

In this study, the purpose of the empirical research was firstly to test and validate the model developed (indicated in 
Figure 2) and, secondly, to determine whether there is a relationship between organisational culture and occupational health (somatic symptoms, anxiety and insomnia). The empirical research design and population as well as the research questionnaires and statistical analyses are discussed.

\subsection{Research design and population}

The survey method was deemed the most appropriate empirical research method to achieve the research aim. The research was conducted in nine regions of a South African information and communications technology (ICT) organisation. The population for the study was defined as the total number of staff in the regions and included all job levels of staff. The population comprised 462 staff members. Owing to operational requirements, and the fact that the staff members were deployed in nine different regions, the questionnaires were made accessible on an online website for a period of two weeks. The different regions also received hard copies of the questionnaires to be administered to those employees who did not have internet access.

According to De Vos, Strydom, Fouche and Delport (2002), out of a population of approximately 500, 20\% (100 respondents) should participate in the research in order to be representative of the population. In this research study, 184 staff members completed the questionnaires. This represented a sample of $39.8 \%$ of the population.

\subsection{Research questionnaires}

The survey research method involved the administration of the General Health Questionnaire and the South African Culture Inventory to the respondents. According to Church and Waclawski (1998, p. 5), a survey is "a systematic process of data collection to quantitatively measure specific aspects of organisational members' experience as they relate to work".

The General Health Questionnaire, developed and published by David Goldberg in 1988 (Goldberg \& Williams, 2006), was adapted to meet the requirements of the organisation concerned. This was done by excluding questions relating to severe depression. The General Health Questionnaire consisted of 21 items to measure three dimensions, namely somatic symptoms, anxiety and insomnia, and social dysfunction. Each of the dimensions consisted of a number of statements combined to provide a total score for each dimension.

The South African Culture Instrument (SACl) assesses organisational culture in terms of leadership, achieving objectives, management processes, employee needs and objectives, vision and mission, and external environment, as well as a diversity strategy that is a vital factor because of South African employment equity standards that have to be adhered to (Martins and Von der Ohe, 2003).

\subsection{Statistical analysis}

Different statistical analyses were conducted to address the aims of testing the theoretically developed model and, secondly, to determine whether there is a relationship between organisational culture and occupational health (somatic symptoms, anxiety and insomnia). The following statistical techniques were deemed appropriate for this research: (1) descriptive statistics; (2) factor analysis; (3) the Cronbach's alpha; (4) SEM, to confirm the exploratory factor structure and the theoretically justified model; and (5) regression analysis.

\section{Results}

\subsection{Factor analysis and reliability}

To determine the factorability and the sampling adequacy, the Kaiser-Meyer-Olkin measure of sampling adequacy and Bartlett's test of sphericity were conducted for both questionnaires. Both the indicators portray adequate scores. For both questionnaires, scree plots were used to determine the number of factors that should be included in the measurement. Principal axis factoring was postulated and the factor matrix obtained was rotated to a simple structure by means of a varimax rotation. The Cronbach's alpha was subsequently used to determine the internal reliability of the two measuring instruments. The results of the number of items per construct, as well as the reliability analysis, are indicated in Tables 1 and 2 below. 
Table 1: Biographical and demographical profile of the respondents $(n=455)$

\begin{tabular}{llcc}
\hline Variable & Category & Frequency $(f)$ & Percentage (\%) \\
\hline \multirow{2}{*}{ Gender } & Male & 322 & 70.8 \\
& Female & 133 & 29.2 \\
\multirow{4}{*}{ Race } & African & 173 & 38.0 \\
& Coloured & 60 & 13.2 \\
& Indian & 42 & 9.2 \\
\multirow{4}{*}{ Generation } & White & 180 & 39.6 \\
& Baby Boomers & 152 & 33.4 \\
& Generation X & 248 & 54.5 \\
\multirow{2}{*}{ Level } & Generation Y & 55 & 12.1 \\
& Management & 35 & 7.7 \\
& Operational & 284 & 62.4 \\
& Specialist & 99 & 21.8 \\
& Supervisor & 37 & 8.1 \\
\hline
\end{tabular}

Table 2: The Kaiser-Meyer-Olkin (KMO) measure of sampling adequacy (MSA) and Bartlett's test of sphericity of the $\mathrm{SACl}$

\begin{tabular}{lcc}
\hline Kaiser-Meyer-Olkin measure of sampling adequacy & \multicolumn{2}{c}{.9523} \\
& Approx. chi-square & 18352.356 \\
Bartlett's test of sphericity & Df & 1770 \\
& Sig. & 0.000 \\
\hline
\end{tabular}

The results of the factor analysis revealed that 19 constructs represented organisational culture. The results are indicated in Table 1 and were as follows: vision and mission; core values and key success factors; control; communication; decision making; innovation; employee needs and objectives; client focus; corporate social investment; physical environment; training and development; people management; management of change; organisational structure; support services; manager versus worker; interdepartmental relationships; diversity; and leadership. The results of the reliability analysis show that the construct reliability coefficients ranged from 0.699 to 0.967 . As explained elsewhere, the recommendation for a suitable criterion for established instruments is around 0.70 (Hair et al., 1998). The Cronbach's alpha may decrease to 0.60 in research such as exploratory research (Hair et al., 1998). The results confirmed the validity and reliability of the two measuring instruments and were also consistent with earlier research.

\subsection{Structural equation modelling (SEM)}

The AMOS statistical program was used for the development of SEM. SEM analysis follows a logical sequence of five steps or processes, as indicated below, which were followed in this research.

\subsubsection{Model specification}

The first step in SEM analysis entails using all the relevant theory, research and information to develop a theoretical model. Hence, before the researcher starts collecting or analysing data, the particular model needs to be designed using the existing information. A given model is properly specified when the true population model is deemed consistent with the implied theoretical model being tested (Schumacker \& Lomax, 2010).

\subsubsection{Model identification}

The parameters in the specified model must be identified. If all the parameters are identified, the model is called an identified model. A parameter is identified when it takes on a single value, given the model and observed data (Hoyle, 2012). 


\subsubsection{Model estimation}

The goal of model estimation is to find values for the free parameters that minimise the discrepancy between the observed covariance matrix and the estimated or implied covariance, given the model and the data (Schumacker \& Lomax 2010).

\subsubsection{Model testing}

Once the parameter estimates have been obtained for a specified model, the researcher should determine how well the data fit the model. In other words, to what extent is the theoretical model supported by the sample data obtained? There are two areas to consider. Firstly, it is necessary to consider a global-type omnibus test for the fit of the entire model. Secondly, the parameters of the model need to be examined (Schumacker \& Lomax, 2010).

\subsubsection{Model modification or specification}

The evaluation of fit can send the researcher in one of two directions, namely interpretation and reporting or modification. Although interpretation and reporting are the desired direction, often the evaluation of fit does not support the specified model and any alternatives, which will lead to modification. The modification requires reconsideration of identification, and then a return to estimation and evaluation of fit (Hoyle, 2012).

According to Garson (2009), the advantages of SEM, compared to a technique such as multiple regression analysis, are as follows: more flexible assumptions; use of confirmatory factor analysis to reduce measurement error by having multiple indicators for each latent variable; the attraction of the SEM graphical modelling interface; the desirability of testing models overall as opposed to individual coefficients; the ability to test models with multiple dependents; the ability to model mediating variables instead of being restricted to an additive model; the ability to model error terms; the ability to test coefficients across multiple between-subjects groups; and the ability to handle difficult data. The SEM strategy of comparing alternative models to assess relative model fit also makes it more robust.

According to Hox and Bechger (1998), although SEM software and inexpensive computers make it easy to apply SEM to all sorts of data (which can have a positive impact on research) this also makes it easy to misuse the technique, especially if the researcher is not aware of all the technicalities. In this study, the first model's goodness of fit indices, which are reported, produced an adequate fit. Hence no further modification was needed, and the first model will be reported on here. The results of the goodness of fit indices applicable to this study are discussed:

The comparative fit index (CFI) .931 was above the conventional .90 cut-off, which reflects an outstanding model fit.

The incremental fit index (IFI) was above the .90 acceptable level. The IFI value of .932 thus reflects an adequate fit.

The relative fit index (RFI), also known as RHO1, is not guaranteed to vary from 0 . to 1 . An RFI close to 1 indicates a good fit (Garson, 2009). The RFI was .857, which indicates an adequate fit.

The cut-off scores of the Tucker-Lewis index (TLI), also known as the NNFI, can be as low as .80 because TLI tends to run lower than CFI (Garson, 2009). A widely accepted cut-off score for a good model fit is above .95 (Hooper et al., 2008). The TLI value was .922, which reflects an adequate fit.

The parsimony-normed fit index (PNFI) addresses the issue of parsimony by taking the complexity of the model into account in its assessment of goodness of fit (Byrne, 2001). In this study, the parsimony goodness of fit (PCFI $=.883$ ) was higher than $>.50$, which indicates a good parsimonious fit (a model with relatively few parameters to estimate in relation to the number of variables and relationships in the model).

According to Byrne (2001), the root square error of approximation (RMSEA) takes into account the error of approximation in the population. A good model fit for RMSEA is less than or equal to .05 (Garson, 2009). The hypothesised model (RMSEA $=.076)$ indicated an adequate model fit.

The goodness-of-fit statistic, CMIN (minimum discrepancy), represents the likelihood ratio test statistic, most commonly expressed in a chi-square (X2) statistic (Byrne, 2001). In this study, the model chi-square was 2.031, which indicated that the model was acceptable. CMIN should be between 2 and 3 for an acceptable fit (Garson, 2009). Given the above interpretation of the various indices, the researchers concluded that the proposed model was acceptable.

In interpreting the regression coefficients and squared multiple correlations (Figure 3, Tables 3 and 4), health appears to have had a smaller impact on social dysfunction, explaining $25.5 \%$ of the variance compared with anxiety and insomnia, explaining $68.6 \%$ of the variance, and somatic symptoms, explaining $68.8 \%$ of the variance (see also the 
squared multiple correlations in Table 4). Furthermore, when interpreting the regression coefficients, organisational culture appears to have had a smaller impact on technical environment, explaining $82.5 \%$ of the variance, and task systems, explaining $87.7 \%$ of the variance, as well as change management, explaining $89 \%$ of the variance. Organisational culture appears to have had a greater impact than organisational strategy, explaining $90 \%$ of the variance, and interpersonal relations, explaining $96.6 \%$ of the variance, as well as management processes, explaining $99 \%$ of the variance (see Table 4).

In interpreting the regression coefficients, change management had a smaller impact on innovation process, explaining $76 \%$ of the variance, and a greater impact on management of change, explaining $80.8 \%$ of the variance.

When interpreting the regression coefficients, interpersonal relations had a smaller impact on interpersonal relations, interdepartmental relations, explaining $58.9 \%$ of the variance, as well as training and development, explaining $59.7 \%$ of the variance. Interpersonal relations had a greater impact on interpersonal relations: diversity, explaining $65.6 \%$ of the variance, as well as interpersonal relations: manager versus worker, explaining $65.4 \%$ of the variance.

In interpreting the regression coefficients, management process had a smaller impact on communication, explaining $66.7 \%$ of the variance, decision making, explaining $54.6 \%$ of the variance, as well as formulate objectives, explaining $66.6 \%$ of the variance. Management process had a greater impact on employee needs and objectives, explaining $69.4 \%$ of the variance, as well as people management, explaining $75 \%$ of the variance.

The regression coefficients of organisational strategy had a smaller impact on mission, explaining $70.7 \%$ of the variance, and core values, explaining $73.9 \%$ of the variance. Organisational strategy had a greater impact on goals, explaining $77.9 \%$ of the variance. The regression coefficients of task systems had a smaller impact on leadership, explaining $51.4 \%$ of the variance, and a greater impact on organisational structure, explaining $73.6 \%$ of the variance. The regression coefficients of technical environment had a smaller impact on physical environment, explaining $36.8 \%$ of the variance, and support services, explaining $45.6 \%$ of the variance. Technical environment had a greater impact on external environment, explaining $47.2 \%$ of the variance. The significant differences for the standardised regression weights are indicated in Table 4.

The correlations are depicted in Table 3 and indicate mostly high correlations for the culture dimensions. The lowest correlation was for social dysfunction.

Table 3: Descriptive statistics and reliabilities of the SACI

\begin{tabular}{lcccccc}
\hline Dimension & N & Mean & Std deviation & Skewness & Kurtosis & Cronbach alphas \\
\hline Leadership & 455 & 3.54 & 0.84670 & -0.649 & -0.036 & 0.944 \\
Strategy and change management & 455 & 3.06 & 0.81108 & -0.358 & -0.411 & 0.914 \\
Employee needs & 455 & 2.83 & 0.86572 & -0.105 & -0.807 & 0.889 \\
Means to achieve objectives & 455 & 3.02 & 0.77416 & -0.248 & -0.514 & 0.862 \\
Management processes & 455 & 3.30 & 0.71433 & -0.388 & -0.195 & 0.860 \\
Organisational goals & 455 & 3.99 & 0.65500 & -0.697 & 1.360 & 0.727 \\
External and internal environment & 455 & 3.60 & 0.75434 & -0.442 & 0.184 & 0.790 \\
\hline
\end{tabular}

Table 4: Results of Kruskal-Wallis test for dimensions of organisational culture

\begin{tabular}{lcccccc}
\hline \multicolumn{1}{c}{ Dimension } & \multicolumn{3}{c}{ Mean } & Chi-square & df & Asymp. sig. \\
\cline { 2 - 5 } & Baby Boomers & Generation X & Generation Y & & & \\
\hline Leadership & 3.50 & 3.44 & 3.96 & 15.799 & 2 & $0.000^{*}$ \\
Strategy and change management & 3.09 & 2.97 & 3.41 & 15.584 & 2 & $0.000^{*}$ \\
Employee needs & 2.95 & 2.67 & 3.20 & 20.833 & 2 & $0.000^{*}$ \\
Means to achieve objectives & 3.04 & 2.95 & 3.29 & 8.2575 & 2 & $0.016^{*}$ \\
Management processes & 3.33 & 3.24 & 3.49 & 7.436 & 2 & $0.024^{*}$ \\
Organisational goals & 3.94 & 4.00 & 4.09 & 5.698 & 2 & 0.058 \\
External and internal environment & 3.59 & 3.58 & 3.72 & 2.453 & 2 & 0.293 \\
\hline
\end{tabular}

$$
\text { * } P<0.05
$$

The results of the regression analysis (Figure 3 and Table 4) indicate that change management, interpersonal relations, management processes, organisational strategy, task systems and technical environment had a significant causal relationship with organisational culture as the dependent variable. The results of the organisational culture subdimensions (Figure 3) also indicated significant relationships with the main organisational dimensions. Social dysfunction, 
anxiety and insomnia as well as somatic symptoms indicated a significant causal relationship with health as the independent variable.

Figure 3: SEM of Organisational Culture

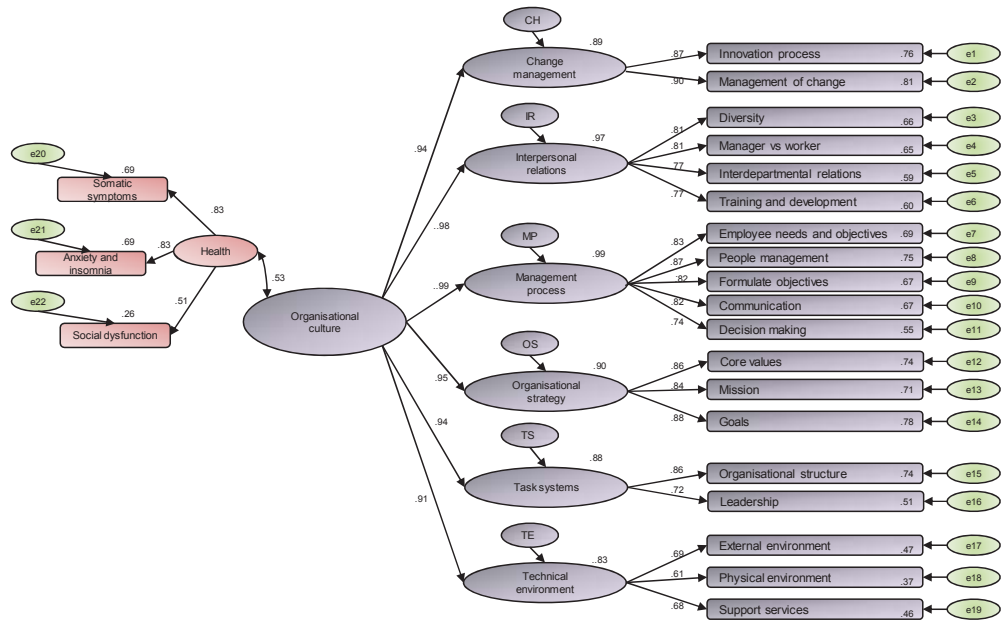

The regression model, which forms part of the SEM process (Table 4), thus confirmed the possible existence of causal relationships between the dimensions. Intercorrelations in SEM indicated that they were all significant, with $p$-values below .05 at the 00 (two-tailed) levels. This confirms the theory that organisational culture can have an impact on occupational health, and vice versa.

Table 5: Kruskal-Wallis test: Comparison between generational cohorts and the dimensional items

\begin{tabular}{|c|c|c|c|c|c|c|c|}
\hline \multirow[t]{2}{*}{ Dimension } & \multirow[t]{2}{*}{ Abbreviated Statements } & \multicolumn{3}{|c|}{$\begin{array}{c}\text { Generation cohort } \\
\text { means } \\
\end{array}$} & \multirow[t]{2}{*}{$\begin{array}{l}\text { Chi- } \\
\text { square }\end{array}$} & & \multirow[t]{2}{*}{$\begin{array}{l}\text { Asymp } \\
\text { sig }\end{array}$} \\
\hline & & $\begin{array}{c}\text { Baby } \\
\text { Boomers }\end{array}$ & $\begin{array}{c}\text { Generation } \\
\mathrm{X}\end{array}$ & $\begin{array}{c}\text { Generation } \\
\mathrm{Y} \\
\end{array}$ & & & \\
\hline \multirow[t]{9}{*}{ Leadership } & Sets an example & 3.56 & 3.48 & 3.98 & 8.312 & 2 & $.016^{\star}$ \\
\hline & Does a good job at people management & 3.56 & 3.52 & 3.93 & 6.735 & 2 & $.034^{*}$ \\
\hline & Is competent & 3.83 & 3.75 & 4.24 & 8.760 & 2 & $.013^{*}$ \\
\hline & Removes obstacles & 3.65 & 3.52 & 4.07 & 11.442 & 2 & $.003^{\star}$ \\
\hline & Encourages subordinates to give their opinion & 3.72 & 3.63 & 4.22 & 14.642 & 2 & $.001^{*}$ \\
\hline & Does a good job of managing the work & 3.78 & 3.55 & 4.02 & 11.184 & 2 & $.004^{*}$ \\
\hline & Have the necessary leadership skills & 3.30 & 3.21 & 3.87 & 16.926 & 2 & $.000 *$ \\
\hline & Purposeful action to make contact with employees & 3.09 & 2.94 & 3.85 & 26.522 & 2 & $.000^{*}$ \\
\hline & Informs how new plans will affect work & 3.22 & 3.02 & 3.85 & 21.333 & 2 & $.000^{*}$ \\
\hline \multirow[t]{5}{*}{$\begin{array}{l}\text { Strategy and change } \\
\text { management }\end{array}$} & The vision to lead the company successfully & 3.16 & 3.13 & 3.65 & 11.333 & 2 & $.003^{*}$ \\
\hline & Keeps employees informed about th & 3.22 & 3.09 & 3.67 & 12.443 & 2 & $.002^{*}$ \\
\hline & Takes purposeful action to integrate core values & 3.37 & 3.27 & 3.65 & 6.340 & 2 & $.042^{*}$ \\
\hline & The company is managed effectively & 2.80 & 2.69 & 3.31 & 14.085 & 2 & $.001^{*}$ \\
\hline & Those affected by decisions are consulted & 2.82 & 2.59 & 3.15 & 13.058 & 2 & $.001^{*}$ \\
\hline \multirow[t]{3}{*}{ Employee needs } & Remuneration is fair & 3.05 & 2.55 & 3.07 & 18.208 & 2 & $.000^{*}$ \\
\hline & Equal opportunities have become a reality & 2.80 & 2.34 & 2.80 & 16.109 & 2 & $.000^{*}$ \\
\hline & Doing what it says regarding equal opportunities & 2.76 & 2.41 & 2.82 & 10.803 & 2 & $.005^{\star}$ \\
\hline
\end{tabular}




\begin{tabular}{|c|c|c|c|c|c|c|c|}
\hline & Cares for it employees & 3.19 & 2.96 & 3.55 & 12.281 & 2 & $.002^{*}$ \\
\hline & Trust relationship exists & 2.91 & 2.67 & 3.29 & 15.370 & 2 & $.000^{*}$ \\
\hline & Contribution in identifying outputs & 3.09 & 2.79 & 3.31 & 12.909 & 2 & $.002^{*}$ \\
\hline & Recruitment without discrimination & 2.78 & 2.71 & 3.49 & 19.594 & 2 & $.000^{*}$ \\
\hline \multirow{2}{*}{$\begin{array}{l}\text { Means to achieve } \\
\text { objectives }\end{array}$} & Activities of divisions are coordinated & 2.93 & 2.84 & 3.29 & 7.864 & 2 & $.020^{\star}$ \\
\hline & Performance evaluated objectively & 3.02 & 2.87 & 3.45 & 14.062 & 2 & $.001^{*}$ \\
\hline \multirow{3}{*}{$\begin{array}{l}\text { Management } \\
\text { processes }\end{array}$} & Ensure the success of chang & 3.22 & 3.12 & 3.58 & 10.714 & 2 & $.005^{\star}$ \\
\hline & Retain best workers & 2.70 & 2.54 & 3.00 & 8.992 & 2 & $.011^{*}$ \\
\hline & Delegate power & 3.24 & 3.18 & 3.58 & 8.555 & 2 & $.014^{*}$ \\
\hline \multirow[t]{2}{*}{$\begin{array}{l}\text { External and internal } \\
\text { environment }\end{array}$} & $\begin{array}{l}\text { Satisfied with the company's involvement in the } \\
\text { community }\end{array}$ & 3.56 & 3.69 & 3.91 & 6.469 & 2 & $.039 *$ \\
\hline & Shares success with the community & 3.53 & 3.56 & 3.89 & 8.013 & 2 & $.018^{*}$ \\
\hline
\end{tabular}

${ }^{*} \mathrm{P}<0.05$

The correlations indicated in table 5 are significant, given the fact that the p values are below 0.05 at the .001 (1\%) levels. This furthermore confirms the theory that health can have an impact on organisational culture, and vice versa.

\subsection{Multiple regression analysis}

Multiple regression analysis was performed (Table 6) to determine the degree to which different dimensions predict occupational health. The purpose was to obtain further confirmation of the conclusions drawn from the SEM.

Table 6: Multiple Regression Analysis

\begin{tabular}{lcccccc}
\multicolumn{1}{c}{ Model } & Standardised coefficients & T & Sig. & \multicolumn{2}{c}{ Collinearity statistics } \\
& Beta & & 7.851 & .000 & & \\
TIF
\end{tabular}

The following dimensions appear to be significant (p-values less than a .05 value) and would predict occupational health, which means that should an organisation focus on these two dimensions, occupational health could be improved:

\subsection{Organisational strategy}

\subsubsection{Task systems}

Furthermore, the results of the multiple regression analysis indicated that interpersonal relations (beta $=-.170)$ and management processes (beta $=-.013$ ) had a negative impact on occupational health. This is an indication that a focus on these dimensions might in fact influence occupational health negatively.

\section{Discussion}

For the purpose of establishing a possible relationship, SEM was used. SEM involves the following two phases: (1) the causal processes under investigation are represented by a series of structural equations; and (2) these structural relations can be modelled pictorially to provide a clearer conceptualisation of the theory being studied (Byrne, 2001). The model displayed the impact of health and organisational culture on its various subdimensions. The indices indicated that the proposed model could be accepted, which confirmed that health can have an impact on organisational culture or vice versa. 
In interpreting the regression coefficients and squared multiple correlations, health appears to have a smaller impact on social dysfunction, compared with anxiety and insomnia and somatic symptoms in this organisation. It thus appears that anxiety, work dysfunction and somatic disorders will influence occupational health in this organisation to a greater extent than a person's interaction with the environment. Interaction with the environment is typically not so important in an ICT organisation compared to, for instance, a bank.

Furthermore, when interpreting the regression coefficients for organisational culture, it appears that organisational culture has a smaller impact on technical environment and task systems as well as change management than on interpersonal relations and management processes. The results thus indicate a greater impact on the softer aspects of organisational culture regarding interpersonal relations (diversity, manager versus worker, interdepartmental relationships and training and development) and the management process (employee needs and objectives, people management, formulation of objectives, communication and decision making). This stands in contrast to the more task-orientated and technical dimensions, which indicate a lesser impact.

The correlation analysis, furthermore, showed significant correlations between organisational culture and health. This confirmed the theory that health can have an impact on organisational culture, or vice versa.

The multiple regression analysis results showed that organisational strategy and task systems, as dimensions of organisational culture, predict occupational health the most. A focus on these dimensions and the subdimensions can thus have a positive influence on occupational health in this organisation. This makes sense if the organisation's strategy can, in the future, focus on occupational health and its implementation by means of focused objectives. It is also important to note that interpersonal relations and management processes had a negative effect on occupational health, which indicates that a focus on the two dimensions might not improve occupational health in future. On the other hand, a focus on these two dimensions could influence the current organisational culture positively.

\subsection{Limitations and suggestions}

Owing to the limitations of the study, and specifically to the fact that limited literature was available on the relationship between organisational culture and occupational health, it is recommended that further research on this topic should be conducted. In an attempt to address some of the limitations, it is further recommended that research on this topic should be conducted in a number of organisations across different industries/environments. Only 21 questions of the General Health Questionnaire (GHQ-28) were used, owing to the exclusion of psychiatric symptoms. This should be taken into consideration when interpreting the data. It would also be helpful to include questions on psychiatric symptoms in any further research in other industries/environments.

The research methodology applied in this research should enable other researchers to apply SEM in order to make a contribution to research and solve other organisational challenges. SEM contains a variety of powerful analysis techniques which could have a positive impact on more applied fields (Hox, 2007). This is supported by Ledimo and Martins (2013), who encourage the use of SEM as an important statistical procedure in theory development in order to generate new models that will assist managers and practitioners to deal with and solve organisational challenges.

\section{References}

Barling, J. \& Griffiths, A. (2003). "A history of occupational health psychology", in Quick, J.C. and Tetrick, L.E. (Eds), Handbook of Occupational Health Psychology, American Psychological Association, Washington DC.

Byrne, B.M. (2001). Structural Equation Modeling: Basic Concepts, Applications, and Programming, Lawrence Erlbaum Associates, London.

Cameron, K.M. \& Quinn, R.E. (2011). Diagnosing and Changing Culture: Based on the Competing Values Framework, (3rd ed.). JosseyBass, San Francisco.

Church, A.H. \& Waclawski, J. (1998). Designing and Using Organizational Surveys, Jossey Bass, San Francisco.

Cummings, T.G. \& Worley, C.G. (2005). Organizational Development and Change, Thomson, Mason, OH.

De Vos, A.S., Strydom, H., Fouche, C.B. \& Delport C.S.L (2002). Research at Grass Roots, Van Schaik, Pretoria.

Garson, G.D. (2009). "Structural equation modelling", from StatNotes: Topics in Multivariate Analysis [Online] Available: http:/lfaculty. chass.ncsu.edu/garson/PA765/structur.htm (accessed 12 January 2012)

Goldberg, D. \& Williams P. (2006). A User's Guide to the General Health Questionnaire, GL Assessment, London.

Grawitch, M.J., Ledford, G.E., Ballard, D.W. \& Barber, L.K. (2009). "Leading the healthy workforce: the integral role of employee involvement", Consulting Psychology Journal: Practice and Research, Vol. 61 No. 2, pp. 122-135.

Hair, J.F., Jr., Anderson, R.E., Tatham, R.L. \& Black W.C. (1998). Multivariate Data Analysis, 5th ed., Prentice Hall, Englewood Cliffs, NJ.

Hartnell, C.A., Ou, A.Y. \& Kinicki, A. (2011). "Organisational culture and organisational effectiveness: a meta-analytical investigation of 
the competing values framework's theoretical compositions", Journal of Applied Psychology, Vol. 94 No. 4, pp. 666-694.

Hooper, D., Coughlan, J. \& Mullen, M. (2008). "Structural equation modelling: guidelines for determining model fit", Electronic Journal of Business Research Methods, Vol. 6 No. 1, pp. 53-60.

Hox, J.J. (2007). "An introduction to structural equation modelling", Family Science Review, Vol. 11, pp. 354-373.

Hox, J.J. \& Bechger, T.M. (1998). "An introduction to structural equation modeling", Family Science Review, Vol. 11, pp. $354-373$.

Hoyle, R.H. (Ed.) (2012). Handbook of Structural Equation Modeling, Guilford Press, New York.

Jackson, L.T.B., Rothmann, S. \& Van de Vijver, F.J.R (2006). "A model of work-related well-being for educators in South Africa", Stress and Health, Vol. 22, pp. 263-273.

Keyton, J. (2011). Communication and Organizational Culture: A Key to Understanding Work Experience, (2nd ed.). Sage, Thousand Oaks, California.

Kinnear, C. \& Roodt, G. (1998). "The development of an instrument for measuring organisational inertia", Journal of Industrial Psychology, Vol. 24 No. 2, pp. 44-54.

Ledimo, O. and Martins, N. (2013). "Application of the structural equation model to develop an employee satisfaction diagnostic model", in Proceedings of the $12^{\text {th }}$ European Conference on Research Methodology for Business and Management Studies, University of Minho, Guimaraes, Portugal, pp. 192-201.

Leka, S., Griffiths, A. \& Cox. T. (2003). Protecting Worker's Health, Series 3, World Health Organisation, Nottingham.

Martins, N. \& Coetzee, M. (2007). "Organisational culture, employee satisfaction, perceived leader competency and personality type: an exploratory study in a South African engineering company", SA Journal of Human Resources, Vol. 5 No. 2, pp. 20-32.

Martins, E. \& Martins, N. (2002). "An organisational culture model to promote creativity and innovation", SA Journal of Psychology, Vol. 28 No. 4, pp. 58-65.

Martins, N. and Von der Ohe, H. (2003). "Detecting sub-cultures in an organisation", South African Business Review, Vol. 10 No. 2 , August, pp. 130-149.

Mathis, R.L. \& Jackson, J.H. (1982). Personnel: Contemporary Perspectives and Applications, (3rd ed.). West Publishing, Saint Paul.

Oginska-Bulik, N. (2005). "The role of personal and social resources in preventing adverse health outcomes in employees of uniformed professions", International Journal of Occupational Health and Environmental Health, Vol. 18 No. 3, pp. 233-240.

Prilleltensky,l. \& Prilleltensky, O. (2006). Promoting well-Being: Linking personal, organizational and community change. Englewood, Cliffs, NJ: Wiley.

Quick, J.C. \& Tetrick, L.E. (Eds.) (2003). Handbook of Occupational Health Psychology,American Psychological Association, Washington DC.

Quick, J.C., Macik-Frey, M. \& Cooper, C.L. (2007). "Managerial dimension of organisational health: the healthy leader at work", Journal of Management Studies, Vol. 44 No. 2, pp. 189-205.

Schein, E.H. (1990). Organizational culture, American Psychologist, Vol. 45 No. 2, pp. 109-119.

Schumacker, R.E. \& Lomax R.G. (2010), A Beginner's Guide to Structural Equation Modeling, (3rd ed.). Taylor and Francis Group, New York.

Shaw, M. (1997). Finding the Rainbow. Organisational Culture: The Key to Corporate Performance, Ravan Press, Johannesburg.

Winnubst, J.A.M. \& Diekstra, R.F.W. (1998). "Work and health psychology: methods of intervention, in Drench, P.J.D., Thierry, H. and De Wolf, C.J. (Eds.), Organizational Psychology, Psychology Press, Hove. 